\title{
HILGARDIA
}

A Journal of Agricultural Science Publisbed by the California Agricultural Experiment Station

\section{STUDIES ON CONTROL OF THE GIANT AFRICAN SNAIL ON GUAM}

\author{
GEORGE D. PETERSON, JR.
}


The giant African snail, Achatina fulica Bowdich, is endemic to the coastal area of continental Fast Africa. The species occurs from southern Abyssinia and the southern half of Italian Somaliland, throngh Kenya and Tanganyika, to northern Portuguese East Africa. The snail's ancestral hemeland also probably includes certain of the small islands lying off the Fast African Coast, including Zanzibar and Pemba, where is is now found. Most probably, it was carly transported by man to Madagascar. Its later introduction, usually deliberately, by man to Bauritius, Reunion, southern Asia, and the Pacific is a matter of historic record. The snail is now known from the Seychelles, Comores. India, Ceylon, Malaspia, Java, Sumatra, Borneo, Siam, Indo-China, China, Formosa, Japan, the Philippines, New Guinea, Micronesia, the Ryukys, the Bonins, and I Hawaii.

The damage done hy snails to crops and ornamental plants wherever they have been introduced has run into millions of dollars. Not only are the snails voracious feeders, they are also capable of extremely rapid reproduction under favorable conditions. Due to their ability to survive even protracted ocean voyages as unsuspected stowaways in war salvage, scrap metal, plant produce, and other materials, there is a very real chance that they may be introduced into continental United States from almost any point in the Pacific. Indeed, the snails have reached California several times, hut alert plant quarantine action resulted in their inmediate destruction. We necd, therefore, to know as much as possible about their control in other areas in the event they hecome established here. 


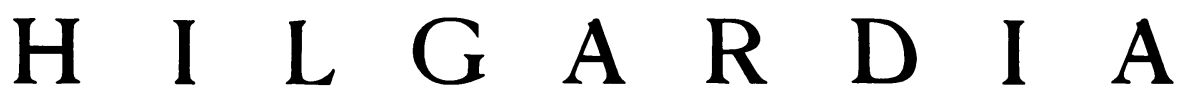

A Journal of Agricultural Science Published by

the California Agricultural Experiment Station

VoL. 26

JULY, 1957

No. 16

\section{STUDIES ON CONTROL OF THE GIANT AFRICAN SNAIL ON GUAM ${ }^{1}$}

\author{
GEORGE D. PETERSON, JR. ${ }^{2}$
}

\section{INTRODUCTION}

The GIANt African snail, Achatina fulica Bowdich, a serious pest of various economic and ornamental plants, became established on Guam during World War II. It is not definitely known if the snail was introduced during the Japanese occupation of Guam or after American military forces recaptured the island. The earliest record of A. fulica on Guam which the author has been able to find is a report by Joaquin Guerrero dated December 20, 1945. ${ }^{\mathrm{B}}$ According to this report, Guerrero conducted an investigation in the vicinity of the village of Santa Rita on December 18, 1945, following receipt of information that large snails had been found there. He reported A. fulica to be abundant at the edge of the village, with the snails inflicting heavy damage to garden crops and certain wild vegetation.

Guerrero's report presents evidence that Achatina fulica may have been introduced during the Japanese occupation. He gives an account of his interview with one Jose I. Shimizu, a Japanese half-caste and an old resident of Guam. Shimizu stated that his father, a Japanese national, had learned of the accidental importation of snails with sweet potatoes from the island of Rota in 1943 and had informed the Japanese Governor-Commandant of his discovery. Shimizu also stated that while he was imprisoned at the Island Command Stockade following American reoccupation of Guam, he overheard Japanese prisoners of war telling of their having eaten snails while they were hiding in the jungle.

It is possible that one or more accidental introductions of Achatina fulica were made by American military forces after the reoccupation of Guam. Snails could have been brought to Guam from Saipan, Tinian, or Rota in any of the numerous shipments of military equipment and war salvage materials which were made from those islands to Guam after the war. Whatever the means of its entry, however, the snail multiplied rapidly and soon was recognized to be a serious threat to the agriculture of the island. Vigorous measures were taken by the Military Government to

\footnotetext{
${ }^{1}$ Received for publication November 16, 1956.

${ }^{2}$ Assistant Agriculturist in the Extension Service, El Centro, California. (Formerly staff entomologist for the Guam Department of Agriculture from April, 1951, to May, 1955.)

"See "Literature Cited" for citations, referred to in the text by author and date.
} 


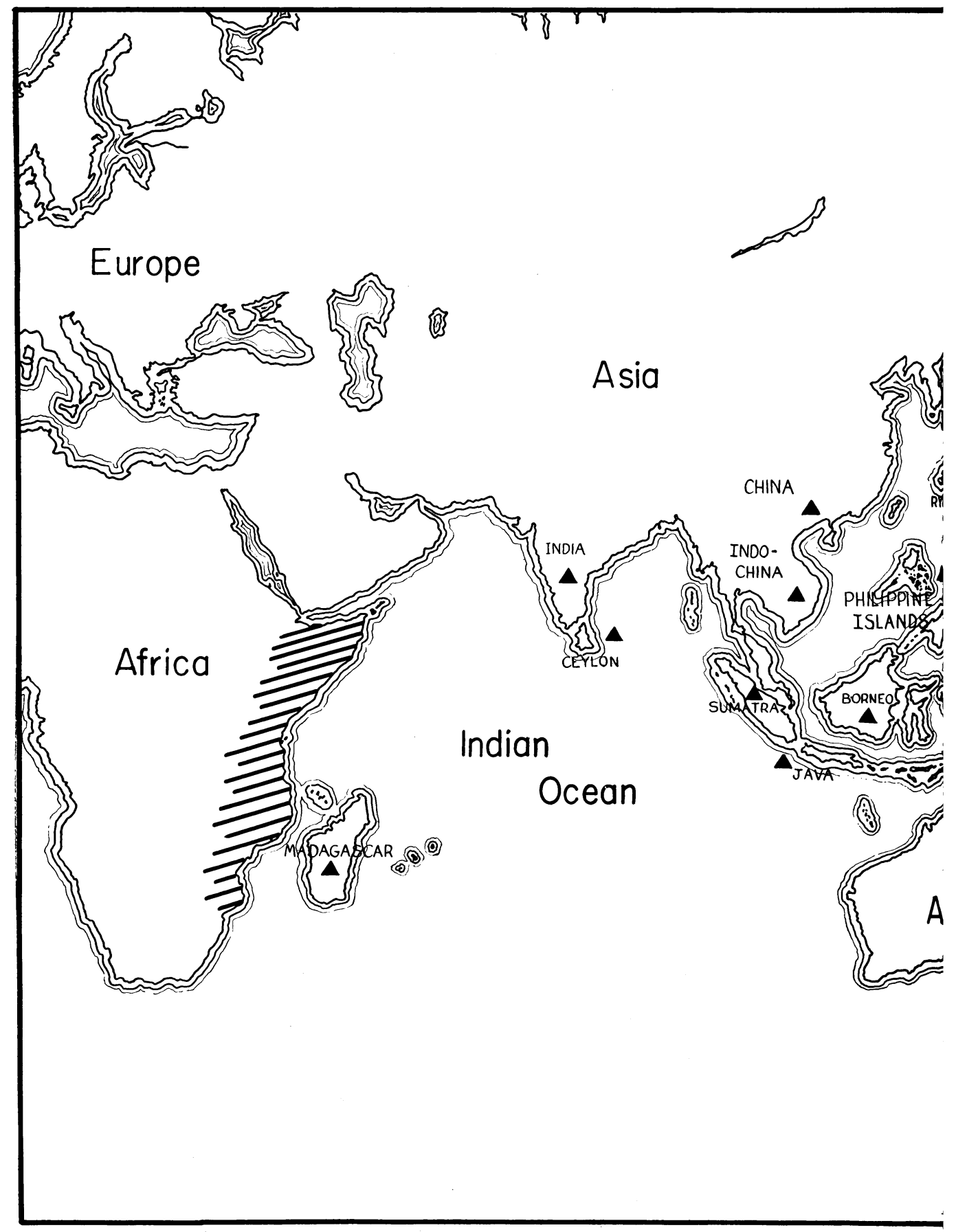

These are the areas in the South Pacific where the giant African Snail has become established. 


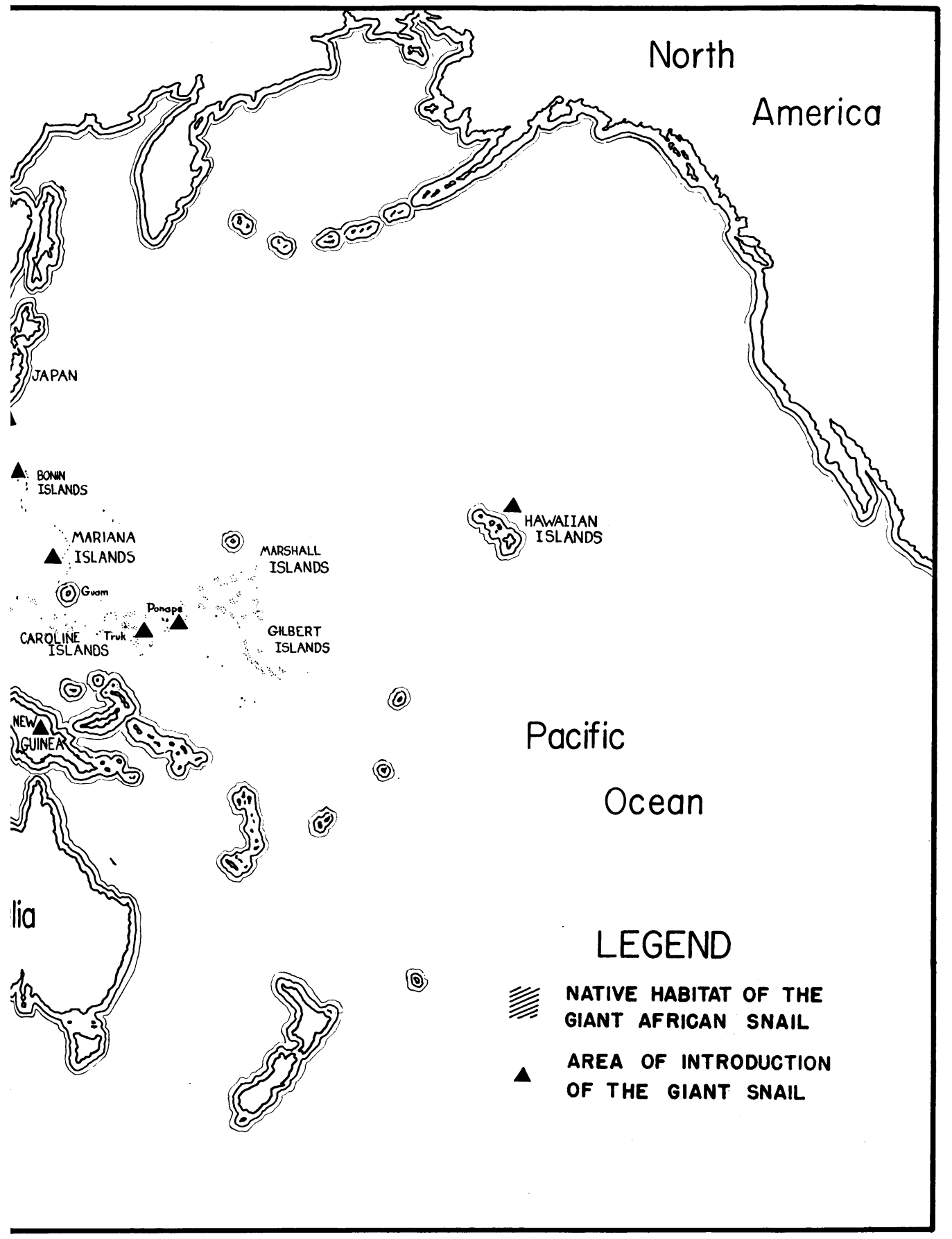


eradicate the snails. Despite these efforts they continued to multiply and to spread until in a few years practically the entire area of the island was heavily infested.

\section{ERADICATION PROGRAM}

In a report dated February 5, 1946, Fred C. Hadden, entomologist, United States Commercial Company, Guam, stated that Achatina fulica had occupied an area near the village of Santa Rita approximately $1 / 2$ mile long by $1 / 4$ mile wide. He recommended that a trail 10 feet wide be cut around this area 300 feet beyond the point where any snails had been found and that systematic poisoning of the snails be conducted with a commercial mollusicide containing metaldehyde. He also recommended that poisoning of the snails be accompanied by the destruction of all vegetation within the

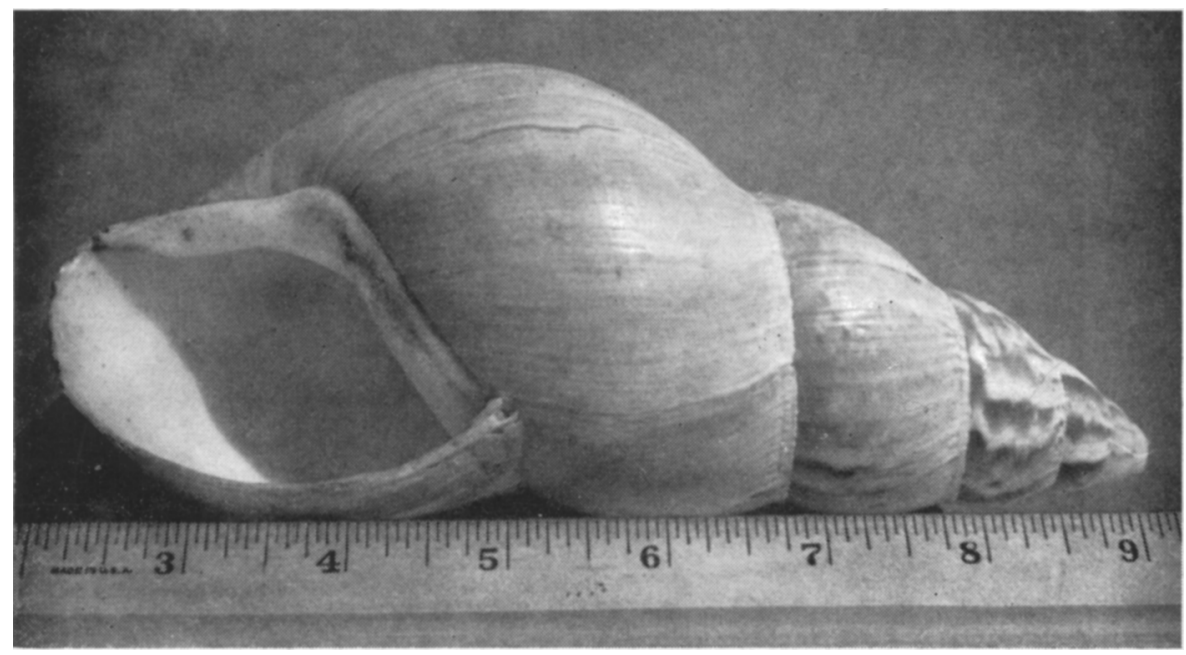

Fig. 1. Achatina fulica Bowdich. This specimen, collected on Guam in 1955, is one of the largest ever found. It measures $195 \mathrm{~mm}$ in length.

infested area by spraying with sodium arsenite or by setting torch to the area. This proposed eradication program was initiated in March, 1946, by the United States Commercial Company at the request of the Military Government. On February 26, Guerrero had discovered a snail infestation in Etton Valley near Agana. In July the snails were found in a third areaAnigua-also near Agana.

Within a very few years all of Guam, except the southern-most portion, was saturated with snails. The Talofofo River, a wide, deep stream whose source is far into the mountainous interior of southern Guam, was a natural barrier to the spread of the snails southward on the eastern side of the island. A line of mountain peaks extends from the western side, in a more or less southeastward direction, for almost the entire width of the island. The southern and western slopes of these mountains are covered almost entirely with swordgrass (Miscanthus sp.) which is unpalatable to the snails and the slopes are extremely arid during much of the year. These natural barriers slowed the onward march of the snails, and it was not until 1953 that 
they became established in the southern end. During the summer of that year a large quantity of water pipes which had been stacked in the open in a snail-infested area was trucked into the Malojlo district to be used in extending a waterline into the village of Inarajan. A few months thereafter, a relatively large area in the vicinity was found to be infested with snails. Undoubtedly, some snails were transported in the pipes. This center of infestation is rapidly expanding, and it is only a question of time until the rich farming valleys of southern Guam will be overrun with snails.

During the early part of the eradication program abundant labor was available in the form of Japanese prisoners of war. Later, the prisoners were repatriated and it became necessary to replace them with hired Guamanian laborers. This materially reduced the number of personnel engaged in the eradication work. The Military Government was replaced by the reëstablished Naval Government during 1946, and responsibility for the eradication program passed to the Department of Agriculture in the new island government. Reductions in funds necessitated further curtailment of the program, and by September, 1946, all labor essential to the project was being supplied on a volunteer basis by the residents of the three infested areas. This labor source soon dried up, and the program came to an end with its objective unrealized. During the first 6 months of the eradication program several millions of snails were destroyed and the areas of infestation were considerably reduced in size. It is conceivable that had the project been consummated as planned the giant African snail might well have been exterminated.

\section{CONTROL INVESTIGATIONS}

\section{Chemical Control}

Sodium Arsenite. Weber (1954) gives an account of experimental studies made in Hawaii in the attempt to find a suitable control for Achatina fulica. Some of these experiments were paralleled on Guam. The use of sodium arsenite in a 1 per cent spray applied to the ground and vegetation in infested areas gave excellent control. Due to the high toxicity of this preparation it was not considered safe for use in residential areas nor in most farming areas where large numbers of farm animals were permitted to run at large. Practical use of sodium arsenite sprays on military reservations where treated areas could be placed under strict control was demonstrated. Kills approaching 100 per cent were often obtained. Similar spraying with solutions of wettable metaldehyde applied at the rate of 5 pounds per acre proved very effective and safe to vegetation, animals, and humans. The scarcity of power spraying equipment among the local population precluded the widespread use of metaldehyde except by the military.

Metaldehyde and Calcium Arsenate. A commercial poison bait preparation consisting of bran as an attrahent, 1.6 per cent metaldehyde, and 5 per cent calcium arsenate in a pellet form proved highly effective and relatively safe to use. This poison bait was so effective in killing localized infestations of snails that it quickly caught the fancy of the public as well as governmental agencies concerned with the control of snails, and great quantities were imported and sold despite the relatively high cost. The pellets disin- 
tegrated readily during rainy weather, therefore care had to be taken to protect the bait from the rain. A common method used was to place the bait in small piles on a pan or dish under a rude shelter of boards, a box tilted on edge, et cetera, leaving sufficient room for the snails to reach the bait. Following ingestion of the bait, snails usually became paralyzed within 10 to 15 minutes and died within 30 minutes to 1 hour. It was found that migrating snails killed by the bait and left on the ground would be partially eaten by other snails the following night and additional snails would be killed.

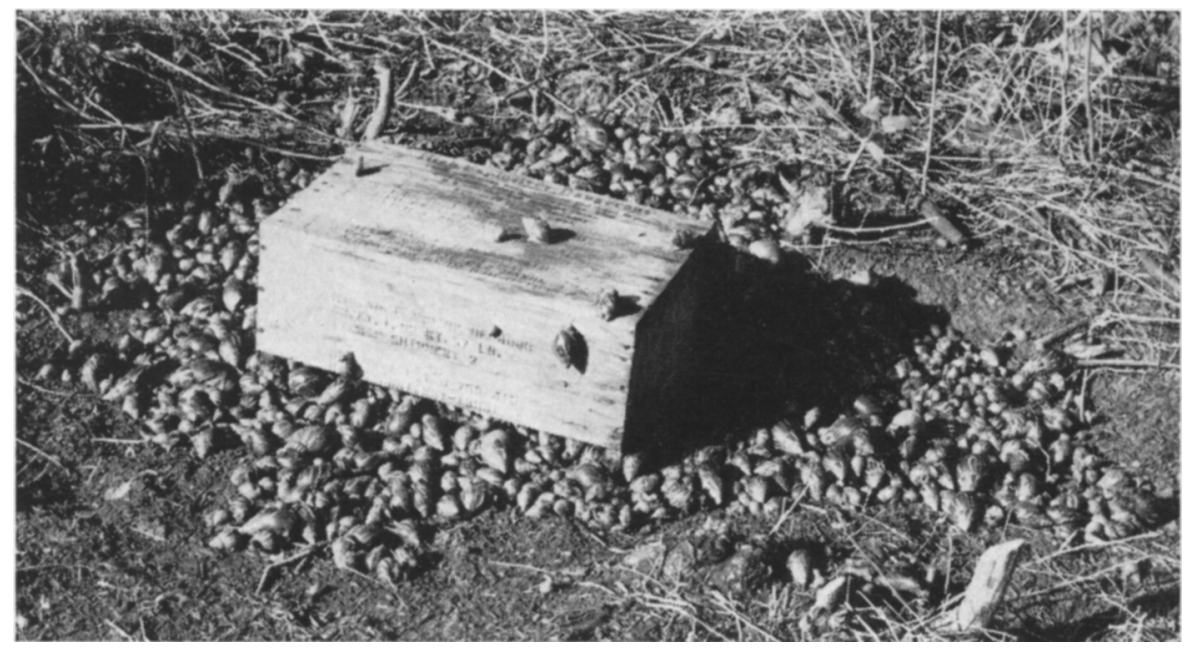

Fig. 2. Snail bait box showing large numbers of snails attracted to the metaldehydecalcium arsenate pellet box. (Photo courtesy of the Brown-Pacific-Maxon Company, Guam.)

A strictly controlled baiting program was carried out by a large construction firm. The company maintained two large residence camps for its personnel, and it was a constant problem to prevent snails from migrating into the camps from the surrounding jungle areas. The snails migrate constantly during the rainy season, and following a heavy rain thousands can be seen on the march-all moving in the same general direction. The procedure adopted to maintain the camps free of snails was a unique one. Empty wooden blasting powder boxes were used to shelter the bait from rain. The boxes were slitted to provide a suitable ground-level entrance for the snails, baited with the calcium arsenate-metaldehyde pellets, and placed at intervals of approximately 15 feet about the perimeter of each camp. Migrating snails were attracted to the bait in such great numbers that they often formed large mounds over the boxes the following morning. Daily rounds were necessary to remove the dead snails and rebait the boxes. The dead snails were hauled away in small jeep-drawn trailers and placed in screened 50-gallon oil drums or large garbage cans where they were allowed to decompose. The resulting evil-smelling nitrogenous liquid was mixed at the ratio of 1 part to 10 parts water and used as a plant fertilizer in the vegetable garden maintained for the camps. 
Combined Rat and Snail Bait. The control of rats on Guam was complicated by the snails. Guam, like many Pacific islands, has a high rat population. During the spring and summer of 1953 , an intensive poisoning program was conducted by the Government of Guam and various coöperating military organizations using a rolled oats bait containing 0.025 per cent warfarin. In preliminary baiting trials in the field it was found impossible to obtain a satisfactory kill of rats in areas thickly infested with snails because the latter were attracted to the bait stations and regularly consumed the war-

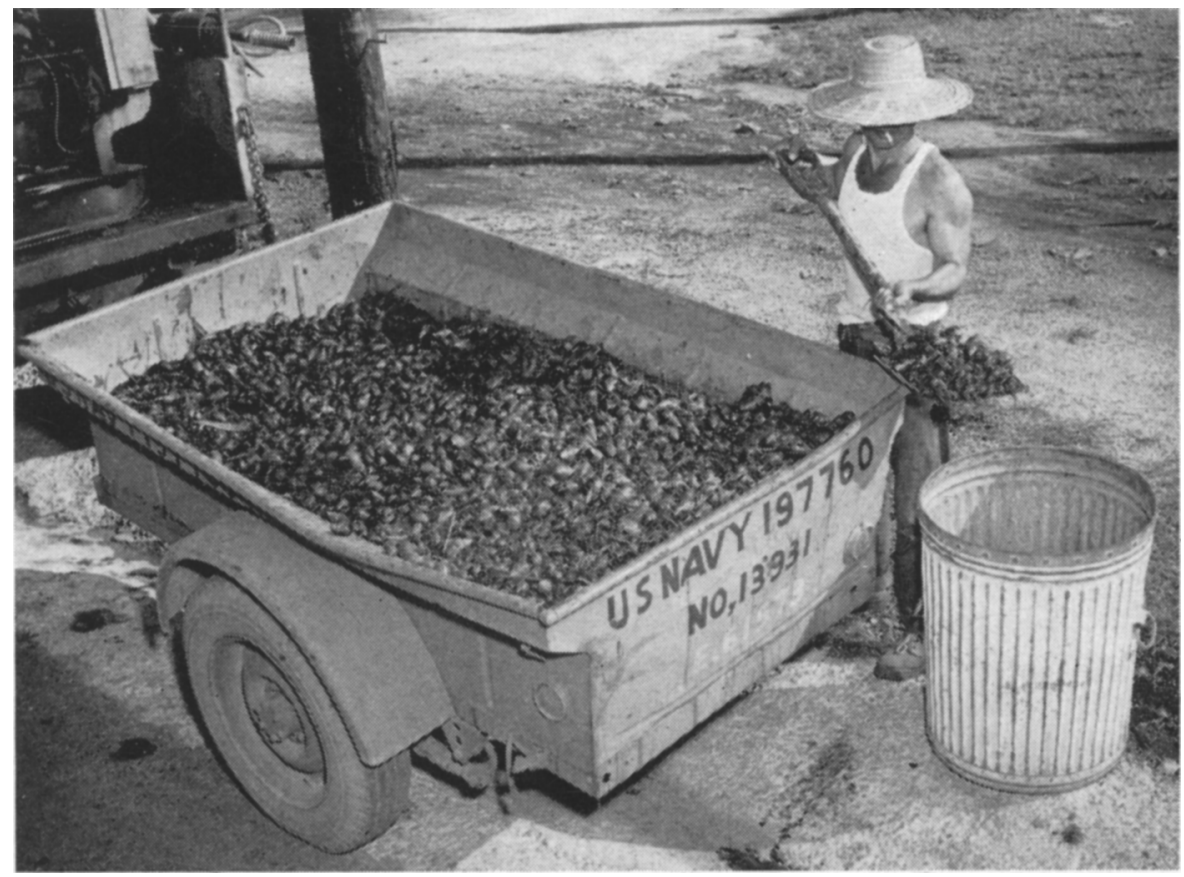

Fig. 3. Part of an average day's collection of snails from the bait boxes. (Photo courtesy of the Brown-Pacific-Maxon Company, Guam.)

farin-rolled oats bait. The same results were obtained with a warfarin bait mixture in which corn meal was substituted for the rolled oats. The poison seemed to have no significant deleterious effect on the snails. It was found expedient to prebait areas containing high populations of snails with metaldehyde-calcium arsenate pellets in order to materially reduce snail population densities before placing the warfarin bait stations in the field. Where there was more or less constant migration of snails into areas in which rat baiting was being conducted, it was frequently advantageous to place snail bait stations parallel to the line of rat bait stations and between the latter and the advancing perimeter of migrating snails. This effectively prevented the majority of the snails from reaching the warfarin bait stations as the metaldehyde-calcium arsenate bait proved more attractive to the snails and deflected them from their approach to the warfarin bait stations. During the course of the rat-control campaign hundreds of thousands of snails were 
destroyed in this manner. This combined use of snail and rat bait was adopted as routine procedure in subsequent permanent controlled rat-poisoning programs of various governmental agencies.

Poisonous Whitewash. Other means of chemical control were tried on an experimental basis. If vegetable gardens were enclosed by a fairly strong fence or rock wall, a preparation consisting of 40 per cent calcium arsenate, 55 per cent slaked lime, and 5 per cent cement mixed with enough water to make a thin paste and applied to the wall or fence as a whitewash would kill snails that tried to rasp off the whitewash. This practice was based on the theory that the snails would be attracted to the calcium in the whitewash which they required for shell building and would be killed when they ingested the arsenic. This method proved rather ineffective because the surface of the ground over much of Guam consists mainly of coral rubble or decomposed coral, consequently, there is a superabundance of calcium available to the snails, thereby lessening the attractiveness of the whitewash.

Wood Ashes and Copper Sulfate. It was found that areas not enclosed by a fence, wall, or similar barrier could be protected temporarily by a line of wood ashes about 6 inches wide and 1 or 2 inches deep on which was sprinkled a 10 per cent solution of copper sulfate. The protection afforded by this method was short-lived because a brisk shower caused the rapid leaching of the copper sulfate from the ashes. Wood ashes alone during periods of dry weather would sometimes serve as an effective mechanical barrier.

\section{Other Methods of Artificial Control}

Salt Water. The use of salt water sprays, either specially mixed or utilizing water from the ocean, proved fairly effective in killing snails. This method frequently caused severe burning of foliage or produce, and, if pursued over a sufficiently long period of time, resulted in poisoning of the soil to plants through the accumulation of salt. It was found to be of some practical use in areas situated near a beach where a plentiful supply of salt water was immediately available and where damage to vegetation or soil was of no consequence, e.g., along roadways.

Hand-picking. There were several other effective ways of combating snails. Daily hand-picking of snails did much to lessen damage. If garden areas or farm plots were surrounded by a belt of cleared land a minimum of 20 feet wide in which absolutely no plants were allowed to grow, invasion of the crop areas usually could be held to a minimum. It was difficult for the snails to cross the bare earth and because of the slowness of their progress many were caught in the open and killed by the heat of the sun.

Window-screen Fences. The use of barriers such as "snail fences" proved very effective in preventing the movement of snails into planted areas. A typical snail fence consisted of a 1-foot-high strip of ordinary wire window screen surrounding the area to be protected. The top 1 inch of the wire was unraveled and every other wire was bent outward at right angles to the screen. The purpose of the unraveling and bending was to provide a barrier of needle-sharp points over which the snails found it impossible to crawl. Window screen was expensive, therefore the use of snail fences was 
best suited for small gardens rather than for larger areas. The fences had to be strongly supported in order to prevent their collapse as the snails surged against them. At times, in areas where there were migrations of unusually great numbers of snails, the snails would sometimes pile up until the topmost layer of snails was higher than the fence when they would then topple into the enclosed area.

Oil Trenches. Large farm plantings or other areas were sometimes protected against snail invasion by rimming them with a shallow trench about 6 to 8 inches deep and 18 inches wide. The banks of the trench were kept cleared of all vegetation and the whole was periodically sprayed with black oil. This proved to be the most effective barrier devised to prevent snails from penetrating an area from which it was desirable to exclude them. Snails were never observed to cross a properly maintained black oil trench.

\section{Biological Control}

During 1947, at the request of the Navy Department, which was then administering the Trust Territory of the Pacific Islands, the Pacific Science Board of the National Academy of Sciences-National Research Council-appointed a committee of entomologists to plan and direct entomological work in the American-administered islands of Micronesia. Originally, the committee was called the "Insect Control Committee for Micronesia," but later came to be designated the "Invertebrate Consultants Committee for the Pacific."

Recognizing the importance of acquiring knowledge concerning the ecology of the giant African snail in Micronesia, the I.C.C.P. arranged for ecological studies to be made in various islands. Lange (1950) investigated the snail on Saipan, Tinian, and Rota during October and November, 1947. Mead and Kondo (1950) conducted further ecological studies of the snail in the Mariana and Caroline islands of the Trust Territory and also in the Bonin Islands during 1949. During the summer of 1951, Chamberlin (1952) made a population study of the snail on Tinian.

Predators. One of the first projects undertaken by the I.C.C.P. was the search for natural enemies of Achatina fulica conducted by Dr. F. X. Williams. Dr. Williams centered his explorations in East Africa, particularly the coast near Mombasa, during the period December, 1947, to June, 1948, and was successful in finding several important predators of the snail. The results of his investigations have been published (Williams, 1953). Several of the more important enemies of A. fulica found by Dr. Williams were shipped or brought by him to Honolulu, Hawaii, where they were placed in a quarantine laboratory for study and propagation. These predators consisted of a beetle of the family Drilidae, the large carabid, Tefflus zanzibaricus sub. sp. alluaudi Sternb., and two species of carnivorous snails of the family Streptaxidae-Gonaxis kibweziensis E. A. Smith and Edentulina affinis C. R. Boettger. The beetles failed to multiply well in the laboratory, but the carnivorous snails were successfully propagated. Experimental studies indicated G. kibweziensis to be the more effective of the two species against Achatina. 
Carnivorous Snails. As a result of the laboratory studies with Gonaxis, the I.C.C.P. concluded that the snail should be given a trial directly in the field in some isolated island in which there occurred a high population of Achatina. Upon the recommendation of Mead and Kondo, the island of Agiguan (Aguijan), which is located about 80 miles north of Guam, was chosen for this experimental study. R. Tucker Abbott was sent to East Africa where he collected and shipped to Guam 545 living Gonaxis. An interesting account of his work has been published (Abbott, 1951). The

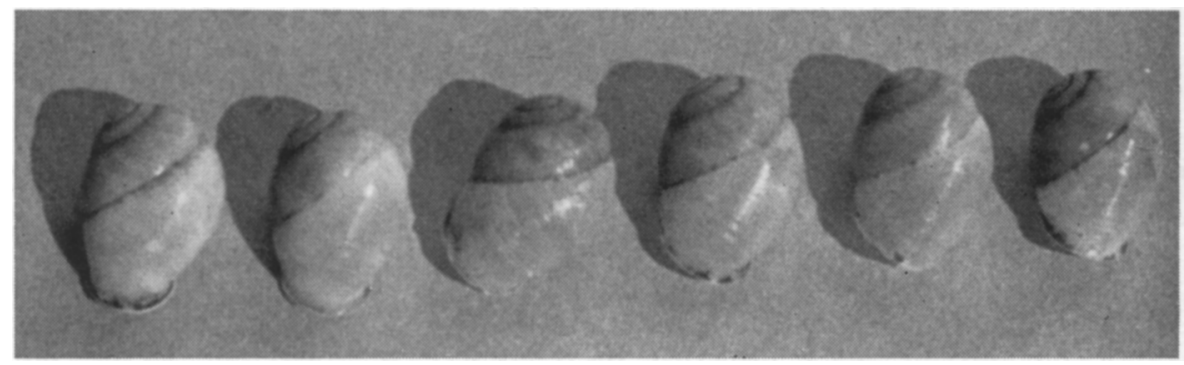

Fig. 4. Gonaxis kibweziensis E. A. Smith, predator of Achatina fulica.

carnivorous snails were received on Guam by $\mathrm{R}$. P. Owen who transported them to Agiguan and there released them on May 31, 1950 (Owen, 1950). About 300 of the snails survived the long trip from Africa. Owen, Chamberlin, and the author confirmed the survival and establishment of Gonaxis on Agiguan during a brief visit to the island in August, 1951.

During May and June, 1952, Kondo, Owen, A. Bronson, and the author spent 17 days on Agiguan investigating the relationship of Achatina and Gonaxis. This study resulted in the development of a scientific method and procedure for population studies of the two snails and provided a preliminary evaluation of the effectiveness of Gonaxis as a predator of Achatina in the field. Investigations were also made into the roles assumed by other animals in the biotic community. This investigation demonstrated that Gonaxis was exerting approximately 20 per cent control over Achatina (Kondo, 1952). Encouraged by these early results, the I.C.C.P. concluded that the Agiguan project should be continued for a minimum of two more years.

In January, 1954, the author was able to visit Agiguan and remain there for 4 days. This very brief investigation revealed that Gonaxis had greatly increased in numbers since 1952 and that Achatina had undergone a drastic population decline (Peterson, 1954). The I.C.C.P. arranged for another major expedition to the island which took place during July and August, 1954. The study team consisted of C. J. Davis, R. Weinrich, and the author. This investigation revealed that Gonaxis was abundant enough to exert considerable control over Achatina and that this control, with all other factors given due consideration, amounted to approximately 60 per cent (Davis, 1954). A high light of this expedition was the collection and shipment to Hawaii with official I.C.C.P. approval of nearly 500 living Gonaxis for release in Achatina-infested areas in those islands. The author in an inde- 
pendent action, carried 122 Gonaxis to Guam for ultimate experimental release in a selected location there. The actual release of the carnivorous snails on Guam was made on September 29, 1954, with the approval of the Guam Department of Agriculture. At the time of release 88 Gonaxis were alive, the remainder having died in quarantine.

The Gonaxis release point on Guam is located on the eastern coast near the Talofofo River. This site was selected after a very careful survey of all areas on Guam which appeared to offer suitable conditions for the establishment and increase of the snails. The release point is located on the northern slope of a densely wooded limestone ridge which rises a mile or so inland and terminates in high bluffs ovealooking Talofofo Bay. Most of the ridge is covered with a thick native forest. Skirting the base of the ridge is a dirt road which runs inland for a distance of several miles. On either side of this road there is a second-growth forest consisting of an almost solid stand of Leucaena glauca (L.) Benth, an introduced leguminous tree. A narrow coastal plain which is under partial cultivation lies between this secondgrowth forest and the ocean. The principal crops grown are bananas, taro, beans, eggplant, and corn. Intermingled with the cultivated areas are thick, mixed growths of trees, shrubs, grasses, and other plants consisting of both native and introduced species. At the time of the Gonaxis release the native forest and the surrounding region were populated with a very high density of juvenile Achatina which are preferred by Gonaxis. The Gonaxis were released in the native forest.

The relative scarcity of the carnivorous snails within the territory occupied by them and the shortness of time since their release preclude the forming of any definite conclusions as to the future of this colony of Gonaxis at the present time. The colony appears to be firmly established, however, and the snails are living under conditions ideal for their survival, multiplication, and spread. They have occupied an area approximately 20,000 square meters in extent and the number of living Gonaxis which have been observed in the release area indicates that their total numbers are now far in excess of those which were released. Empty juvenile Achatina shells are fairly common throughout the Gonaxis territory, particularly at the point of original release. Large numbers of these empty shells undoubtedly represent Achatina killed by desiccation during periods of hot, dry weather; however, it may safely be assumed that a fair percentage of the empty shells represent Achatina killed and eaten by Gonaxis. The colony seems to be following the pattern that was observed on Agiguan. Future investigations will probably reveal a continued enlargement of the territory occupied by Gonaxis and a decline of the Achatina population within that territory.

The I.C.C.P. arranged for the further collection of Gonaxis on Agiguan during November, 1955. Several thousands of the carnivorous snails were subsequently liberated in Hawaii, Guam, and various islands of the Trust Territory. A small colony was shipped to the University of California Citrus Experiment Station, Riverside, for experimental use in the biological control of Helix spp. 
Indian glowworm. The Indian glowworm, Lamprophorus tenebrosus (Walker), has long been known to be an important enemy of the giant African snail. Paiva (1919) gives a good account of the habits of this interesting lampyrid. Hutson and Austin (1924) give an excellent account of its life history and habits, and Bess (1956) has recently published a paper on its ecology. A brief account of its introduction to Guam has been published (Peterson, 1957).

Arrangements were made in January, 1955, for the collection and shipment of Lamprophorus larvae from Ceylon to Guam. The collector and shipper was Dr. Henry A. Bess who was in Ceylon on sabbatical leave. The larvae were collected and shipped via air express during the months of February and March, 1955. A total of six shipments was received from Dr. Bess from which 933 living Lamprophorus larvae were successfully liberated in the field. The glowworms were shipped in wooden boxes about 6 by 6 by 18 inches in size provided with screened ventilating holes along either side. The boxes were divided into three compartments which were loosely filled with dampened wood shavings or sphagnum moss in which the larvae were placed. Mortality per shipment averaged 30 per cent. The boxes were opened immediately upon their arrival at the laboratory on Guam and the glowworms transferred to large glass jars containing suitable numbers of juvenile Achatina. The glowworms fed voraciously after their long journey. Hutson and Austin (1924) mention that Lamprophorus larvae feed mainly on liquids secreted by Achatina when the latter are attacked by the firefly larvae and on the semiliquid contents of the intestine rather than on the flesh of the snails. Lamprophorus larvae held in the laboratory on Guam invariably consumed the snails entirely. After several hours of feeding and reconditioning, the glowworms were taken into the field and liberated. Releases were made in four areas: 116 glowworms were released in the vicinity of Almagosa Springs, 252 at Agana Springs, 134 in the Talofofo River valley, and 431 near Ylig Bay. None of these release points was near the Gonaxis release area.

The Lamprophorus larvae did not survive well in the laboratory. Consequently, no extended studies of their habits could be made. One large glowworm which was held in a plaster of Paris cage in the laboratory for 10 days killed and consumed eight Achatina. Size of the snails eaten varied from 20 to $40 \mathrm{~mm}$. The glowworm did not attack larger snails even when starved. Living Gonaxis adults were also caged with this larva, but were not attacked. Six young glowworms were confined in a plaster of Paris cage with six juvenile Achatina and six juvenile Gonaxis of approximately equal size. Two of the Achatina were killed and eaten by Gonaxis, the other four by Lamprophorus. One Gonaxis was killed and eaten by another Gonaxis. The glowworms eventually died, presumably of starvation, without making any attempt to attack the five remaining Gonaxis. These experiments indicated that Lamprophorus might not prey on Gonaxis in the field.

There is no positive evidence that Lamprophorus is established on Guam. Inspections of the release areas about 2 months after the final release of glowworms was made produced evidence that some of the glowworms had survived. Empty shells of juvenile Achatina which obviously had died very 
recently were fairly numerous at all release points. In one area a number of Lamprophorus were observed and photographed while feeding upon Achatina and native snails. A "nest" of four glowworms was found-one of which was feeding upon a young Achatina-which was surrounded by many freshly eaten snails. All glowworms actually observed in the field were found in the release area at Ylig Bay. This locality seemed particularly favorable for the survival of the firefly larvae. The release point is located at the base

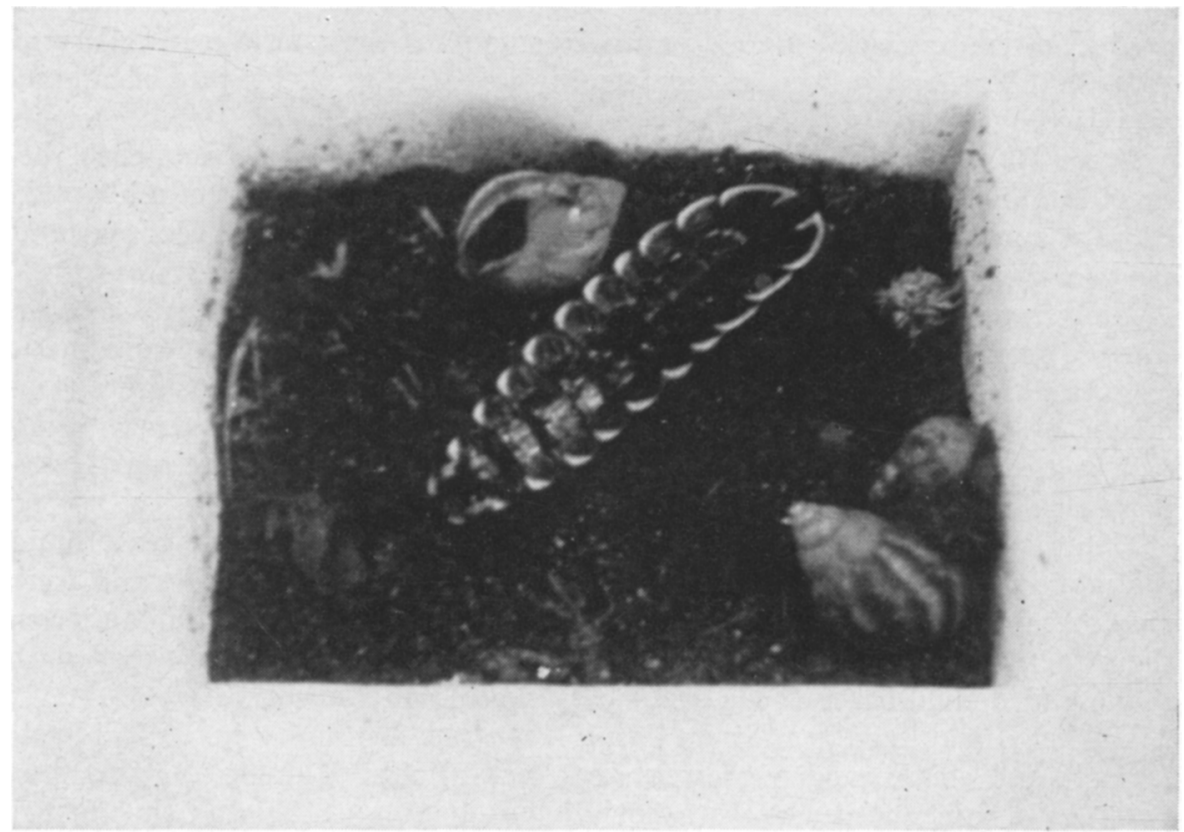

Fig. 5. Lamprophorus tenebrosus (Wlk.). Mature glowworm shown beside a juvenile giant African snail which it has just eaten.

of a limestone ridge which parallels the Ylig River for several miles and terminates near the coast. The ridge is densely covered with a native forest which is being invaded by Leucaena glauca. The forest floor was wet and covered with a thick layer of leaves and humus. There was an extremely high population of Achatina at this point and the snails were very numerous throughout the forest over the entire ridge.

\section{Other Natural Enemies}

Rats and Coconut Crabs.-Kondo (1952) credited rats and coconut crabs (Birgus latro Linnaeus) with effecting 52 per cent control of Achatina on Agiguan based on the presence of vast numbers of crushed and chipped shells. He concluded that most of the Achatina were killed by rats, with only a small percentage attributable to coconut crabs, with the possible assistance of hermit crabs (Cenobita perlatus Edwards) and birds. Since no definite demarcation between shells of Achatina killed by rats and those killed by crabs was known, he applied the term "rat-crab combine" to the 
presumed predators. Davis (1954) cast some doubt on the validity of Kondo's theory with respect to rats based on cage tests conducted with coconut crabs and hermit crabs and the extreme scarcity of rats on Agiguan. The author's own observations on Agiguan lead him to suspect that Kondo may have weighed the evidence too strongly in favor of the rats and that he may have overestimated the total effect of the rat-crab combine on Achatina. There is ample evidence, however, that whatever the individual efficiency of these animals as predators of Achatina may be, their combined predatism cannot be dismissed as unimportant in the over-all mortality of Achatina. Future workers may determine statistically the degree of control exercised by each.

Musk Shrew. The large musk shrew, Suncus murinus (Linnaeus), became established on Guam in 1953 (Peterson, 1956). The shrew multiplied rapidly and by 1955 was common along the western and northern sides of the island and had spread into the interior.

Many reports were received that shrews were killing and eating Achatina. These reports were given careful consideration, and attempts were made to authenticate them but with no success. Field investigations were conducted by the author and his assistants. Shrews were never observed to attack snails in the field, and no evidence was found to substantiate the reports received.

Experimental feeding tests were made in the laboratory. It was found that starved shrews held in cages would attack juvenile Achatina and were able to cause moderate damage to the shells. One small snail did die from the attack of a shrew, but none was actually eaten. All shrews caged with snails and denied other foods eventually died from starvation.

Ducks. Ducks feed readily on living Achatina, especially juveniles. Some farmers and small garden growers kept small flocks of ducks for this purpose. As a rule, the ducks were not allowed to range. Usually, the farmer raked up the snails which had migrated onto his property during the night and fed them to the ducks after they had been crushed. It was not necessary to cook the snails as the ducks relished them raw. Crushed snails which had been boiled were readily acceptable to chickens and pigs.

\section{SUMMARY}

The giant African snail, Achatina fulica Bowdich, a serious pest of economic and ornamental plants, became established on Guam during World War II. An attempt to eradicate the snail during 1945 was unsuccessful. Experiments were conducted to find a suitable chemical control for the snail. Sodium arsenite sprays proved highly effective, but were not considered safe for use in residential and farming areas because of high toxicity to animals and humans. Methaldehyde sprays and a poison bait consisting of bran, methaldehyde, and calcium arsenate proved very effective and relatively safe to use. The use of poisonous whitewashes containing calcium arsenate, barriers of wood ashes sprinkled with a solution of copper sulfate, and salt water sprays proved relatively ineffective in controlling the snail.

Three effective barriers were devised to prevent snails from invading crop areas. These were: a fence consisting of a strip of wire window screen 
1 foot high surrounding the area to be protected, a belt of cleared land about the planted area, and shallow trenches sprayed with black oil about the perimeter of the planted area.

A carnivorous snail, Gonaxis kibweziensis E. A. Smith, was introduced from East Africa to Agiguan Island in the Marianas in 1950, in a project conducted under the auspices of the Invertebrate Consultants Committee for the Pacific, Pacific Science Board. The snail ultimately proved very effective in the control of the giant African snail. A colony of Gonaxis was introduced to Guam from Agiguan in September, 1954, and is now firmly established on Guam. It is too early to know the final outcome of this introduction.

The Indian glowworm, Lamprophorus tenebrosus (Walker), an important enemy of Achatina fulica in India and Ceylon, was successfully introduced from Ceylon to Guam during February and March, 1955. Colonies were released in four areas of Guam. Establishment of Lamprophorus has not been confirmed.

Rats and coconut crabs were demonstrated to be important predators of the giant African snail. Ducks fed readily on the snail and small flocks were maintained by individual farmers as a control measure. No evidence was found that shrews exerted any control over the snail.

\section{LITERATURE CITED}

Аввотт, R. TUCKER

1951. Operation snailfolk. Nat. Hist. $60(6): 280-85$.

Bess, Henry A.

1956. Ecological notes on Lamprophorus tenebrosus (Walker) (Coleoptera: Lampyridae), an enemy of the giant African snail. Hawaii. Ent. Soc. Proc. XVI(1) :2429.

Chamberlin, J. L.

1952. Final report on an ecology and population study of the giant African snail on Tinian, Mariana Islands. Pacific Sci. Board. (Mimeo.)

Davis, C. J.

1954. Report of the Davis expedition to Agiguan. Hawaii. Board of Commissioners Agr. and Forestry. (Mimeo.)

GUERRERO, JoAqUIN

1945. Rept. to U. S. Naval Military Gov't. Unit, Guam. (Typescript)

HADDEN, FRED C.

1946. Rept. to U. S. Naval Military Gov't. Unit, Guam. (Typescript)

Hutson, J. C. and G. Douglas Austin

1924. Notes on the habits and life history of the Indian glow-worm. Ceylon Dept. Agr. Bul. 69.

Kondo, Yoshio

1952. Report on carnivorous snail experiment on Agiguan Island; primary and secondary Achatina-free areas on Rota and gigantism among Achatina on Guam. Pacific Sci. Board. (Mimeo.)

LANGE, W. HARRY, JR.

1950. History and feeding habits of the giant African snail on Saipan. Pacific Sci. IV $(4): 323-35$.

Mead, Albert R., and Yoshio Kondo

1950. Part I. The problem of the giant African snail (Achatina fulica) in Micronesia (by Mead). Part II. The giant African snail (Achatina fulica) in Palau (in part). Pagen and Guam (by Kondo). Pacific Sei. Board. (Mimeo.) 
OWEN, R. P.

1950. Rept. to High Commissioner, Trust Territory of the Pacific Islands. (Mimeo.) PaIva, C. A.

1919. Notes on the Indian glow-worm (Lamprophorus tenebrosus (Wlk.)). Indian Mus. Rec. $16: 19-28$.

Peterson, George D., Jr.

1954. Report on progress of carnivorous snail experiment on Agiguan, Mariana Islands. Pac. Sci. Board. (Mimeo.)

1956. Suncus murinus, a recent introduction to Guam. Jour. Mammal. 37(2):278-79.

1957. Lamprophorus tenebrosus introduced into Guam to combat the giant African snail. Jour. Econ. Ent. $50: 114$.

WEBER, P. W.

1954. Studies on the giant African snail. Hawaii. Ent. Soc. Proc. XV(2):363-67.

Williams, F. $\mathrm{X}$.

1953. Natural enemies of snails of the genus Achatina in East Africa. Seventh Pac. Sci. Cong. Proc. Pacific Sci. Assoc. 4:277-78.

\section{ACKNOWLEDGMENTS}

The author is indebted to the Brown-Pacific-Maxon Company, Guam, for permission to reproduce the two photographs depicting control of the giant African snail by using poison bait. Thanks are also due to C. Harvey Campbell, Jr. for his assistance with other of the illustrations and to $\mathrm{H}$. Barden Wellcome for the map showing distribution of the snail. Appreciation is expressed to Dr. C. E. Pemberton and Professor C. P. Clausen, both of whom reviewed the manuscript and made valuable suggestions. 
The journal Hilsardia is published at irregular intervals, in volumes of about 600 pages. The number of issues per volume varies.

Sulneriptions are not sold. The periodical is sent as published only (1) librarics, or to institutions in foreign countrics having i)ullications to offer in exchange.

You may ohtain a single copy of any issue free, as long as the supply lasts; please request by volume and issue number from:

$$
\begin{aligned}
& \text { Agricultural Publications } \\
& \text { Rom 22, Giannini Hall } \\
& \text { Iniversity of California } \\
& \text { Berkeley t, Califurnia }
\end{aligned}
$$

The limit to nonresidents of California is 10 separate issues on a single oriker. A list of the issues still available will be sent on request.

In our publications it is sometimes convenient to use trade names of products or equipment rather than scientific identifications. In so doing it is unavoidable in some cases that similar products which are on the market under other trade names may not be cited. No endorsement of named products is intended nor is criticism implied of similar products which are not mentioned. 


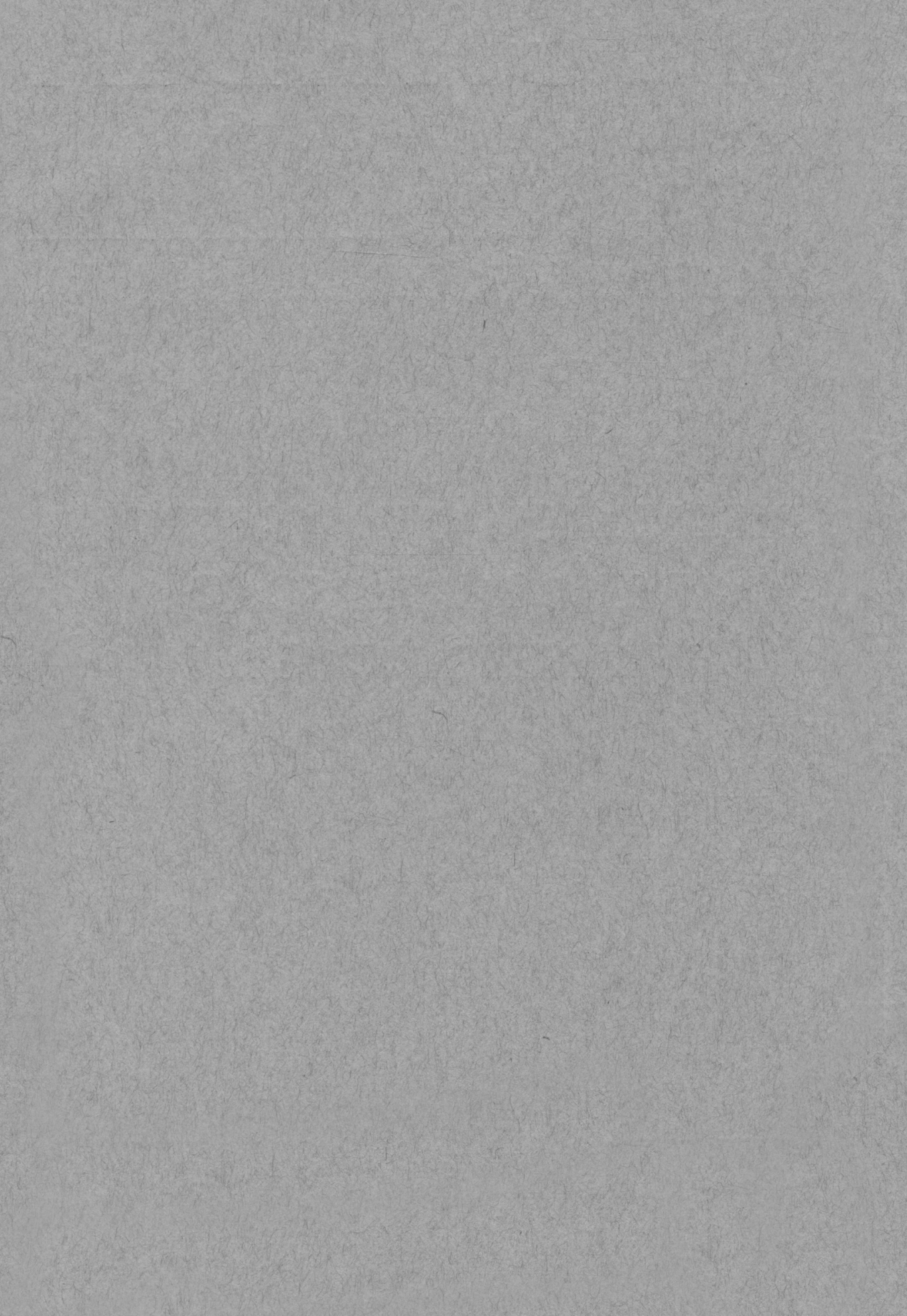

